\title{
SCENTED CORPORATE VISUAL IDENTITY
}

\author{
Urška Stankovič Elesini (D), Tjaša Armič (iD, Raša Urbas \\ University of Ljubljana, Faculty of Natural Sciences and Engineering, \\ Department of Textiles, Graphic Arts and Design, Ljubljana, Slovenia
}

\begin{abstract}
The aim of this research was to create a corporate identity and to enrich it with a coffee fragrance. To reach this goal, microcapsules with coffee essential oil were used. For testing, two types of samples were prepared: business cards, with designed and printed fragranced logotype, and samples with fully printed surface using printing ink enriched with the fragranced microcapsules. The microcapsules and the printed samples were analysed using selected testing methods, scanning electron microscope and sensory test. The sensory test was conducted in an odourless room, during afternoons, over a four-month period. During this pilot study, a questionnaire for respondents was prepared. Business cards were used for company customers, whose response on fragranced items was tested and analysed. From the results obtained during tests we established that the screen printing inks with added fragrant microcapsules emit a recognizable scent over a long period of time, and that their presence as a corporate identity attracts customers and produces positive effects.
\end{abstract}

Key words: coffee essential oil, corporate identity, microcapsules, screen printing

\section{INTRODUCTION}

Fragrance can arouse memories related to previous experiences and emotions. Among all human senses, the scent is most strongly associated with a memorable emotion, and not with the facts. A scent can be associated with a pleasant experience, encouraging a system to refer to certain events and emotions (Ward et al, 2007; Michon et al, 2005). These memories influence the person's mood and can lead to mild changes in well-being, as was showed by Lindstrom (Lindstrom, 2011). He emphasized the importance of smell for the patients with dementia, Alzheimer's disease or amnesia caused by brain injuries in accidents. Lindstrom also emphasized that majority of our preferences for brands and products has been stamped up since the age of seven. Thus, many marketers try to manipulate our preferences also with the smell, which can be used in two ways (Ward et al, 2007): the first is related to the product attributes (e.g. the smell of the fragrant flower) and the other with the environment in which the products are sold (e.g. the smell of the baked bread in the shop). The scent recalls the memory on two stages: the first stage is associated with the recalling positive associations (e.g. the smell of the roasted bread or the boiled coffee), while the second stage recalls comfortable experiences and emotions during shopping (Ward et al, 2007). Bakeries, chocolatiers, florist shops and other specialized stores often have a noticeable smell of products in the sales area, however not all products emit smells, so these are added to the stores as, for example, artificially dispersed scents. Such a way of adding scents to the market environment encourages researchers to analyze and try to determine the psychological and the behavioral impact of the smell on the customer/s (Spangenberg et al, 2006).

Two interesting studies on the effect of the smell were presented in the Mattila and Wirtz studies (Mattila et al, 2001). In the first research, the test persons performed a catalogue purchase in a scented and unscented room. It was established that people in the scented room spent more time than in unscented room. In the second study, the test persons were tested in casinos. As it was concluded from the research, the people on slot machines consumed more money when the casino was pleasantly refined.

The idea for this research stemmed from a desire of Slovenian company, which deals with the coffee machines, to design a recognisable corporate identity, which should possess a suitable scent of fresh coffee that would pleasantly influence on customers. After an extensive literature research and suitable cooperation with the company, the aim of this research was to analyse the scent of coffee on printed products especially its intensity during determined period. For this purpose, the microcapsules with the coffee essential oil in the core were used in the process of printing, while the printed samples and designed business card were tested and analysed on general properties and by sensory test. 


\section{MATERIALS AND METHODS}

\subsection{Materials}

\subsubsection{Microcapsules}

Single core microcapsules were synthesized by modified in situ polymerization. For the microcapsule shells, partially methylated trimethylolmelamine (Melamin, Slovenia) was used. Polyacrylic polymer was used as a modifying agent/poly-condensation initiator for the in-situ polymerization. Analytical grade sodium hydroxide (Kemika, Croatia) was used for the termination of the poly-condensation reaction and $\mathrm{pH}$ neutralization. To remove the formaldehyde released during the poly-condensation, ammonia (Kemika, Croatia) was added to the suspension of the microcapsules as the scavenger. As a core material, laboratory prepared coffee essential oil was used. The modified process of the in situ polymerization microencapsulation was performed in a 1-L laboratory reactor equipped with a turbine stirrer in the following stages: (1) preparation of an aqueous solution of the modifying agent; (2) emulsification of a core material at a room temperature with stirrer speed of $1500 \mathrm{rpm}$ for $20 \mathrm{~min}$; (3) addition of the partly methylated trimethylolmelamine amino-aldehyde prepolymer for the shell formation; (4) induction of the poly-condensation reaction by raising the temperature to $70-80^{\circ} \mathrm{C}$; $(5)$ poly-condensation process (approx. 1 hour) of microcapsules formation; (6) termination of the poly-condensation; (7) removal of the released formaldehyde by addition of an ammonia scavenger at $50^{\circ} \mathrm{C}$; and (8) cooling to the room temperature.

\subsubsection{Paper substrate}

In research paper substrate Flora Avorio (manufacturer Gruppo Cordenon, Italy) was used. The paper was recycled, manufactured from primary wood-free cellulose (60\%), inkless wood-free cellulose (30\%), and cotton fibres (10\%). The declared grammage of the paper substrate was $350 \mathrm{~g} / \mathrm{m}^{2}$ (Flora, 2017).

\subsubsection{Sample preparation}

Although the logotype was specially designed and printed for the company, additional samples were prepared for testing as follows. Microcapsules (suspended in an aqueous solution) in $20 \%$ mass conc. were mixed with printing ink (Elastil Comprente, Minerva, Italy) and pigments in 5\% mass conc. Thus, prepared printing mixture was applied with screen printing to the surface of the paper substrate. The screen printing technique was performed manually. We have used a screen printing PET mesh with the thread density of $36 \mathrm{~cm}^{-1}$ and monofilament diameter $80 \mu \mathrm{m}$, which was fixed to the aluminium frame at the thread angle $0^{\circ}$ and the load tension of $15 \mathrm{~N}$. All prints were made with one passage of the squeegee, and air-dried at $100^{\circ} \mathrm{C}$. Unprinted samples were denoted as PS 350 and printed samples as PS 350S. With each PS 350-SP sample, side A was printed, and side B was unprinted.

\subsection{Methods}

\subsubsection{Microcapsules}

The appearance of the microcapsules was observed by scanning electron microscopy (SEM; JSM 6060 LV, Jeol, Spain). The microcapsule suspension was applied on a specimen stub and allowed to air-dry. The samples were covered with an ultra-thin coating of gold (with high vacuum evaporation). The size of the microcapsules was determined from the SEM images with the use of the ImageJ software and from the results, the size distribution curves were drawn. The release behaviour of microcapsules was performed by tests according to Hwang et al. (2006). For tests, the suspension of the microcapsules was added into the aluminium cups $(5 \times 7 \mathrm{~cm}$ in size), which were then placed into the drying oven. In the release test by Hwang et all. (8), the oven was heated first to $25^{\circ} \mathrm{C}$ and then to $40^{\circ} \mathrm{C}$. The microcapsules were heated for both temperature ranges for 5 days. Each day, at the same time, the samples were weighed and placed back into the oven. With the use of Equation (1), the release rate of the tested microcapsules was calculated:

Mass loss $[\%]=\frac{A_{0}-A_{n}}{A_{0}} \cdot 100$

where $A_{n}$ presents the weight $(\mathrm{g})$ of the microcapsules after $n$ days of the release test $(n=1, \ldots 5$ days) and Ao presents the weight $(\mathrm{g})$ of the microcapsules suspension prior to the release test. 
The first calculated mass loss after the first day corresponds to the water evaporation and the residual material corresponds to the dry mass/share of the microcapsules in an aqueous suspension. Subsequent drying in the 5 days period corresponds to the weight lost after every day due to the porosity of the shell.

\subsubsection{Paper substrate}

Before and after printing, the following properties were measured on the paper substrates: Grammage was measured according to the method described in the standard ISO EN 536:2012 (ISO 536:2012, 2012). Thickness was measured on a Mitutoyo apparatus, No: $2050 \mathrm{~F}-10$, with a load of $500 \mathrm{cN} \cdot \mathrm{cm}^{-2}$ on the sample area of the measurement of $1 \mathrm{~cm}^{2}$ and according to the standard ISO 534:2011 (ISO 534:2011, 2011). Roughness of the paper substrates was determined by the Bendtsen method, as described in the standard ISO 8791-2 (ISO 8791-2:2013, 2013). Air permeance was measured on a Bendtsen apparatus according to the method described in the standard ISO 5636-3 (ISO 5636-3:1992, 1992) Height of a capillary rise was measured in the machine direction (hereinafter $\mathrm{MD}$ ) and cross-direction (hereinafter $\mathrm{CD}$ ) by the Klemm method, according to the standard ISO 8787:1996 (ISO 8787:1996, 1996).

\subsubsection{The sensory test}

Before the sensory test and the samples were prepared, the preliminary test was conducted in the company. This test was performed with the intention to understand how the coffee fragrance influences the mood of employees. For this purpose, three open bags filled with the coffee were put at the main entrance hall of the company for 30 days. At first the employees were pleased with smelling the coffee when entering the company. However, after 14 days, they started to avoid the main entrance hall and entered the company through the back door. We have determined, that the smell was pleasant at the beginning, but after 14 days, the smell become annoying and employees start to avoid it. In contrary, customers that came to the company less frequently recognized the smell of coffee as pleasant each time they came to the main entrance hall of the company.

The sensory test was performed on the printed samples PS 350-SP. In the test 17 respondents participated (7 males and 10 females). For each respondent five samples of the PS 350-SP were prepared (S1 to S5). Testing was performed in the morning, always in the same ventilated room, without any other scents. Samples were stored separately for each respondent and together with their personal questionnaire.

Before starting, precise plan of the testing (shown in Table 1) was developed. Since each respondent rubbed the samples with their fingers, washing hands was compulsory before test. For this senseless soap Balea (Balea, Austria) was used. The rubbing of the samples was performed in the same manner each time (four rubs: left-right-left-right) with the use of only one finger. The scent was determined subjectively by each respondent and classified into one of five classes: scentless, barely perceptible scent, slight scent, strong scent and very strong scent. Testing was performed five times, starting in November 2017 and finishing in March 2018.

Table 1: Sensory test plan

\begin{tabular}{|c|c|c|c|c|c|}
\hline Sample & $\begin{array}{c}\text { Immediately } \\
\text { after printing }\end{array}$ & After 1 months & After 2 months & After 3 months & After 4 months \\
\hline S1 & smell-rub-smell & smell-rub-smell & smell-rub-smell & smell-rub-smell & smell-rub-smell \\
\hline S2 & smell & smell-rub-smell & smell-rub-smell & smell-rub-smell & smell-rub-smell \\
\hline S3 & smell & smell & smell-rub-smell & smell-rub-smell & smell-rub-smell \\
\hline S4 & smell & smell & smell & smell-rub-smell & smell-rub-smell \\
\hline S5 & smell & smell & smell & smell & smell-rub-smell \\
\hline
\end{tabular}

At the same time as sensory test was performed, also a simple test was performed with the customers of the company. For them, business cards were designed and scented in the same way as in the case of samples PS 350-SP (by screen printing). These cards were given to the customers, when came to the company. They expressed their opinion about the scented business card after they got the card and after a period of one month, during which they carried it in their wallets. 


\section{RESULTS}

\subsection{Properties of the microcapsules}

The size distribution of the synthetized microcapsules is presented in Figure 1. As it can be seen from the graph, the highest share of the microcapsules (74.7\%) was in the interval from 0.7 to $11 \mu \mathrm{m}$. Smaller microcapsules are more resistant to the share forces as bigger microcapsules and thus also to the shell rupture. Consequently, the smaller microcapsules longer retain material and fragrance in the core as the bigger microcapsules. Of course, the porosity of the wall of the microcapsules also has an influence on the release of the fragrance: the more porous is the wall, the shorter time the fragrance is released.

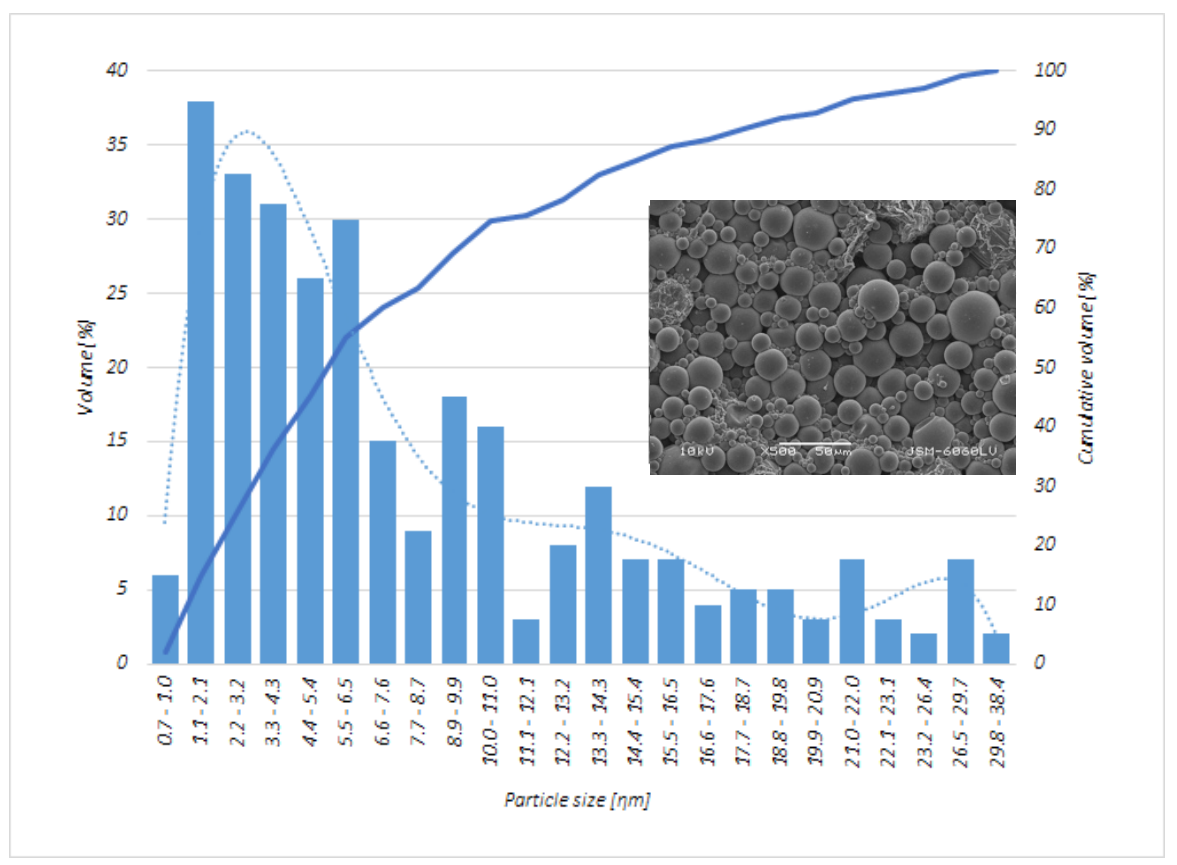

Figure 1: Size distribution and SEM image of the microcapsules with the essential oil of coffee in the core (SEM; 500× magnification)

According to the results in Figure 2, the microcapsules used in our research had a nonporous wall, since only $0.12 \%$ and $0.34 \%$ of the core material at $25^{\circ} \mathrm{C}$ and $40^{\circ} \mathrm{C}$, respectively, were released in 5 days. The drop of the mass loss shown in first day is due to the water evaporation.

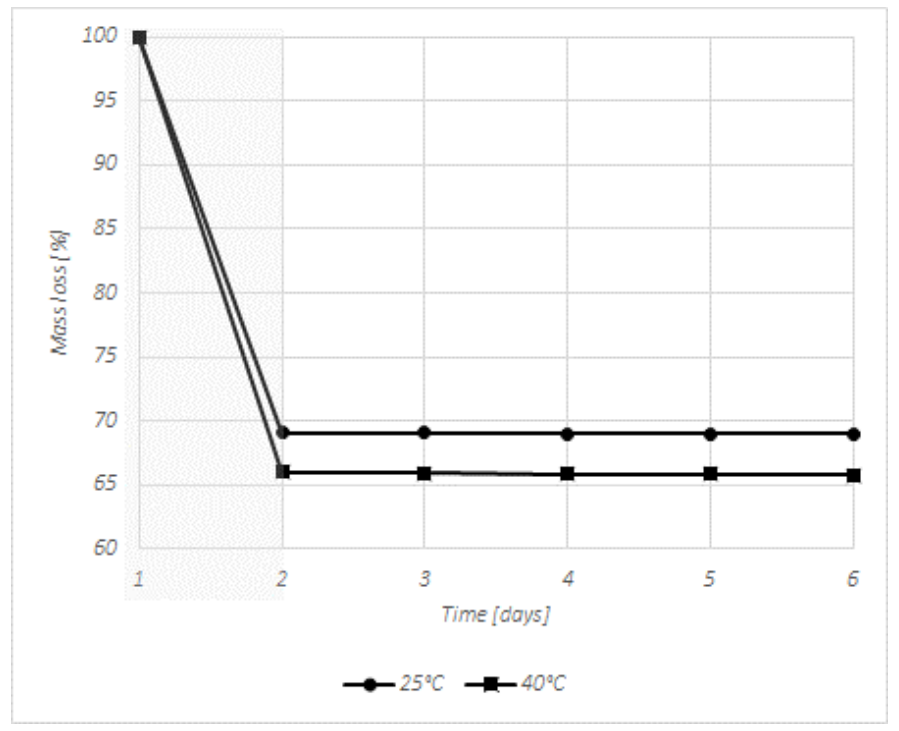

Figure 2: Proportion of the released core material through the microcapsule wall during 5 days, at $25^{\circ} \mathrm{C}$ and $40^{\circ} \mathrm{C}$ 


\subsection{Properties of the paper substrate before and after printing}

The measured properties of unprinted (PS 350) and printed (PS 350-SP) samples are shown in the Table 2. As it can be seen, the paper substrate possesses almost the same capillarity in both directions, MD and CD respectively. After printing the air permeability decreased significantly, while the roughness increased on printed side $\mathrm{A}$ and slightly decreased on unprinted side $\mathrm{B}$.

Table 2: Properties of the samples PS 350 and PS 350-SP (A - printed side, B - unprinted side, MD - machine direction, $C D$ - cross direction)

\begin{tabular}{|l|c|c|}
\hline Property & PS 350 & PS 350-SP \\
\hline Grammage $\left[\mathrm{g} / \mathrm{m}^{2}\right]$ & 338.35 & 373.21 \\
\hline Thickness $[\mathrm{mm}]$ & 0.48 & 0.51 \\
\hline Roughness (Bendtsen) $[\mathrm{ml} / \mathrm{min}]$ & $\mathrm{A}=1450 / \mathrm{B}=1350$ & $\mathrm{~A}=1845 / \mathrm{B}=1215$ \\
\hline Air permeance (Bendtsen) $[\mathrm{ml} / \mathrm{min}]$ & $\mathrm{A}=439.00 / \mathrm{B}=450.00$ & $\mathrm{~A}=37.50 / \mathrm{B}=31.50$ \\
\hline Height of capillary rise $[\mathrm{mm}]$ & $\mathrm{MD}=16.60 / \mathrm{CD}=16.20$ & - \\
\hline
\end{tabular}

\subsection{Results of the sensory test}

In the sensory test, out of 17 involved respondents $82.4 \%$ of them drink coffee. The majority of the respondents (86.2\%) believe that sight is the most important sense during the purchasing of products. $65.5 \%$ mean that the sound is also important, following with the smell (34.5\%), touch and taste. Of course, the importance of each sense is changing according to the type of the product we are purchasing.

$71.4 \%$ of respondents drink coffee two to four times per day, while $28.6 \%$ of respondents drink coffee two to five times per week. $35.3 \%$ of respondents recognised the scent of the coffee during smelling the samples, while $41.2 \%$ of respondents did not recognized the scent. Other respondents (23.5\%) thought that the scent belonged to zirconia, garlic, herbs etc. As pleasant the scent was recognized by $17.7 \%$ of respondents, $29.4 \%$ thought it was interesting and $29.4 \%$ as annoying. Other respondents (23.5\%) did not have any feelings about the scent. On the other hand, $41.4 \%$ of respondents replied that the smell of the coffee reminded them of the break at work, to the new beginnings, breakfast, childhood, parents, beautiful day and nice things.

Intensity of the scent before and after rubbing of the samples was followed for four months. As it can be seen from the Figure 3 (left), the samples were before rubbing scentless, barely or slightly scented after printing and even after four months. This implies, that the scent did not penetrate through the wall of the microcapsules, which coincides with the results of the release test (Figure 2). After the samples were rubbed, the scent was determined again, and the results are shown in the diagram in the Figure 3 (right).
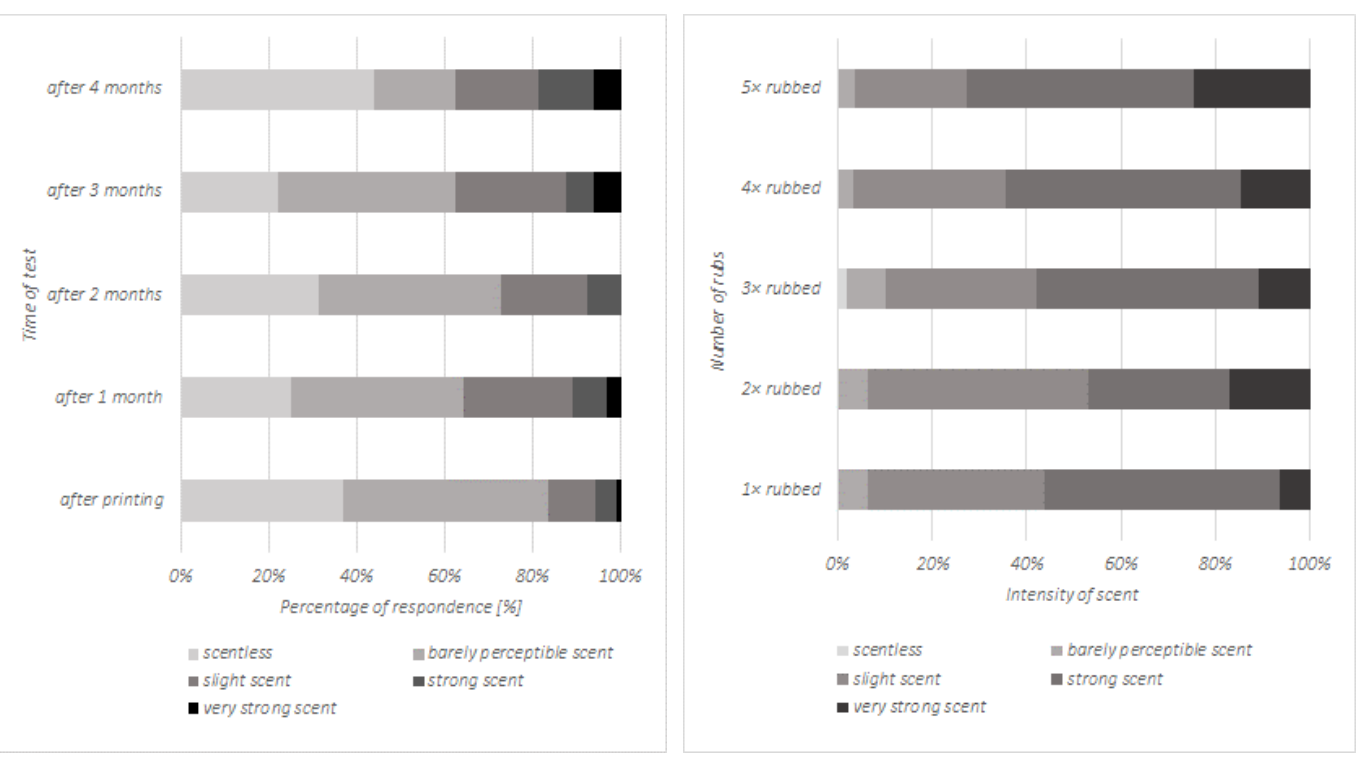

Figure 3: Intensity of the scent of the samples before (left) and after (right) rubbing 
From the diagram it can be seen that the scent after rubbing is slight, strong and even very strong. The microcapsules, which were printed on the surface of paper substrate, were consequently trapped inside the layer of the printing ink. After rubbing some of them were ruptured and the coffee essential oil and also the scent was released from the core and detected during the test. Results show that also after $5 \times$ rubbing, the samples still emitted strong scent which implies, that the microcapsules in different sizes (Figure 1) prolong the emitting time of the scent, since some of the microcapsules can rupture earlier (especially bigger microcapsules) and some of them later (smaller microcapsules).

In our research, the second group of respondents were customers of the company. 13 customers participated in the research (4 males and 9 females). At their visit we gave them scented business cards, and all recognized the smell of coffee. According to the results, none of them have ever sign the scented contract, however $27.6 \%$ of them would certainly sign it and $48.3 \%$ would not although they loved the scented business card.

\section{CONCLUSIONS}

As was shown by the research,

- the pleasant smell is an important factor when purchasing a product or service,

- it is necessary to be careful of where and how the smell of i.e. coffee is used, since even the pleasant smell can become very annoying and thus distracting to the customers,

- the presence of the fragranced microcapsules involved in some elements of the corporate identity attract customers and gives positive effect on them,

- the fragrant microcapsules in different sizes emit a recognizable smell over a longer period even if they are immersed into the printing ink.

\section{ACKNOWLEDGMENTS}

The authors gratefully acknowledge dr. Boštjan Šumiga from the Faculty of Natural Sciences and Engineering, for the microcapsules prepared with the coffee essential oil.

\section{REFERENCES}

[1] International Organization for Standardization, ISO EN 536:2012 Paper and board - Determination of grammage, International Organization for Standardization, 2012.

[2] Flora, Recy \& Tex, Gruppo Cordenons, URL: http://www.gruppocordenons.com/en/products/scheda-prodotto.html?id=2496\&brand_id=38 (last request: 2017-12-01).

[3] Hwang, J. S., Kim, J. N., Wee, Y. J., Yun, J. S., Jang, H. G., Kim, S.H. in Ryu, H.W.: "Preparation and characterization of melamine-formaldehyde resin microcapsules containing fragrant oil", Biotechnology and Bioprocess Engineering 11(4), 332-336, 2006. doi: 10.1007/BF03026249.

[4] International Organization for Standardization, ISO 534:2011 Paper and Board - Determination of thickness, density and specific volume, International Organization for Standardization, 2011.

[5] International Organization for Standardization, ISO 5636-3:1992 Paper and board - Determination of air permeance (medium range) - Part 3: Bendtsen method, International Organization for Standardization, 1992.

[6] International Organization for Standardization, ISO 8787:1996 Paper and board - Determination of capillary rise - Klemm method, International Organization for Standardization, 1996.

[7] International Organization for Standardization, ISO 8791-2:2013 Paper and board - Determination of roughness/smoothness (air leak methods) - Part 2: Bendtsen method, International Organization for Standardization, 2013.

[8] Lindstrom, M.: "Brandwashed: Tricks Companies Use to Manipulate Our Minds and Persuade Us to Buy", (Crown Business, New York, 2011.), pages 21-23.

[9] Mattila, A. S., Wirtz, J.: "Congruency of scent and music as a driver of in-store evaluations and behaviour", Journal of Retailing 77 (2), 273-289, 2001. doi:10.1016/S0022-4359(01)00042-2. 
[10] Michon, R., Chebat, J.C., Turley, L.W.: "Mall atmospherics : the interaction effects of the mall environment on shopping behaviour", Journal of Business Research 58(5), 576-583, 2005. doi: 10.1016/j.jbusres.2003.07.004.

[11] Spangenberg, E. R., Sprott, D. E., Grohmann, B., Daniel, L., Tracy, D. L.: "Gender-congruent ambient scent influences on approach and avoidance behaviors in a retail store", Journal of Business Research 59, 1281-1287, 2006. doi: 10.1016/j.jbusres.2006.08.006.

[12] Ward, P., Davies, B. D., Kooijman, D.: "Olfaction and the retail environment: examining the influence of ambient scent", Service Business 1(4), 295-316, 2007. doi:10.1007/s11628-006-0018-3.

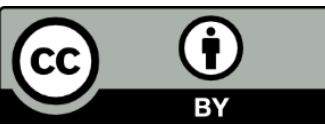

(C) 2018 Authors. Published by the University of Novi Sad, Faculty of Technical Sciences, Department of Graphic Engineering and Design. This article is an open access article distributed under the terms and conditions of the Creative Commons Attribution license 3.0 Serbia (http://creativecommons.org/licenses/by/3.0/rs/). 